\title{
E-test antibiotic susceptibility of E.coli strains isolated from hospital acquired infections of Imam Khomeini hospital, Ilam, Iran
}

Lida Bimanand ${ }^{1}$, Norkhoda Sadeghifard ${ }^{1}$, Farid Azizi Jalilian ${ }^{1}$, Hassan Hossainzadegan ${ }^{2}$, Sattar Mohammadi Darbidi ${ }^{1}$, Ali Hemahian ${ }^{1}$, Sobhan Ghafourian ${ }^{1}$, Iraj Pakzad ${ }^{1,3 *}$

1. Clinical Microbiology Research Center, Ilam University of Medical Sciences, Ilam

2. Department of Microbiology, Faculty of Nursing, Maragheh University of Medical Sciences, Iran

3. Department of Microbiology, Faculty of Medicine, Ilam University of Medical Sciences, Ilam, Iran

*Corresponding author: Tel: +98 8432235714 Fax: +98 8432235714

Address: Department of Microbiology, Faculty of Medicine, Ilam University of Medical Sciences, Ilam, Iran

E-mail: pakzadi2006@gmail.com

Received; 2015/07/5 revised; 2015/08/30 accepted; 2015/10/5

\section{Abstract}

Introduction: Escherichia coli (E.coli) as a main cause of both nosocomial and communityacquired infections in humans have a relative potential to develop resistance. Nowadays, most infections caused by ESBL-producing E.coli (ESBLEC) had mostly been described as nosocomial acquired or nursing home related. In this study, we employed E-test assay to detect antibiotic resistance of E.coli strains and determine MIC of antibiotics.

Materials and methods: Thirty E.coli strains gathered from Imam Khomeini hospital of Ilam, and cultured on TSB and bacterial suspension prepared by $0.5 \mu \mathrm{F}$ concentration for Etest. Mueller Hinton agar and E-test strips of Amikacin, Cefepime, Ceftazidime, Ceftriaxone, Gentamicin, Meropenem, Nitrofurantoin, Piperacillin/Tazobactam, Tetracycline, Ticarcillin/ Clavulanic acid, Tobramycin, Trimethoprim were used

Results: Resistance to Ceftriaxone, Tobramycin, Gentamicin, Ticarcillin/ Clavulanic, Amikacin were $19.8 \%, 26.4 \%, 23.3 \%, 62.7 \%, 70.3 \%$, respectively.

Conclusion: the results indicated, E.coli strains in this study were high sensitivity to Meropenem ,Nitrofuratoin, Ciprofloxacin, Ceftazidime, Cefepime.

Keywords: E-test, Antibiotic susceptibility, E.coli, Ilam, Iran

\section{Introduction}

Escherichia coli (E.coli) as main cause of both nosocomial and community-acquired infections in humans have a relatively large potential for developing resistance $(1,2)$. Urinary tract infection (UTI) is a common cause of morbidity in women (3). Majority of cases involve only the lower urinary tract, and the most common pathogen is E.coli (4). UTI result in approximately 8 million physician visits and more than 100,000 hospital admissions per year in the United States (5).
Nowadays, most infections caused by ESBL-producing E.coli (ESBLEC) had mostly been described as nosocomial acquired (6) or nursing home related (7). In this study, we recruited E-test assay to detect antibiotic resistance of E.coli strains and determine MIC of antibiotics.

\section{Materials and methods}

Sampling: The urine cultures of patients with urinary tract infections in Imam Khomeini hospital of Ilam were selected. Thirty E.coli 
isolates after determined by biochemical standard tests were used.

Antibiotic susceptibility testing by E.test strip: Antibiogram was performed by KirbyBauer disk diffusion method using Clinical Laboratory Standard Institute (CLSI) criteria. E.coli isolates was cultured on Muller Hinton broth and bacterial suspension prepared by $0.5 \mu \mathrm{F}$ concentration for $\mathrm{E}$ test. Suspension of bacteria were cultured on Mueller Hinton agar by swab and Etest strip of amikacin, amoxicillin, cefepime, ceftazidime, ceftriaxone, gentamicin, meropenem, nitrofurantoin, piperacillin/tazobactam, tetracycline, ticarcillin/clavulanic acid, tobramycin, sulfamethaxazole-trimethoprim were used (Table 1).

\section{Results}

Table 1 shows the MIC of recruited antibiotics in this study and Table 2 shows result of MIC for isolated strains.

Table 3 indicated $4(13.33 \%)$ strains were resistance, $8(26.66 \%)$ strains were intermediate and other strains were susceptible for TX. 3(10\%) of strains were resistance, $13(43.33 \%)$ were intermediate and other were susceptible for TM .

$2(6.66 \%)$ were resistance to MP. $4(13.33 \%)$ were resistance, $10(33.33 \%)$ were intermediate to $\mathrm{TZ}$ but other strains shown susceptibility pattern. 3(10\%) strains were resistance to GM. All of strains shown susceptibility toVA and LZ.

Table 1. Utilized antibiotics in this study.

\begin{tabular}{|c|c|c|c|c|c|c|c|}
\hline $\begin{array}{c}\text { ANTIBIOTIC } \\
\mu \mathrm{g} / \mathrm{ml}\end{array}$ & Code & $\mathrm{S} \leq$ & I & $\mathrm{R} \geq$ & \multicolumn{2}{|c|}{ Quality Control } & $\mu \mathrm{g} / \mathrm{ml}$ \\
\hline $\begin{array}{c}\text { amikacin } \\
0.016-256\end{array}$ & AK & 16 & 32 & 64 & E.coli & ATCC25922 & 1.4 \\
\hline $\begin{array}{c}\text { cefepime } \\
0.002-32 \text { or } \\
0.016-256\end{array}$ & PM & 8 & 16 & 32 & E.coli & ATCC25922 & $0.016-0.064$ \\
\hline $\begin{array}{c}\text { ceftazidime } \\
0.016-256\end{array}$ & $\mathrm{TZ}$ & $\begin{array}{l}8 \\
2\end{array}$ & $\begin{array}{c}16 \\
-\end{array}$ & $\begin{array}{r}32 \\
-\end{array}$ & $\begin{array}{l}\text { E.coli } \\
\text { P.aeruginosa } \\
\text { H.influenzae }\end{array}$ & $\begin{array}{l}\text { ATCC } 25922 \\
\text { a ATCC } 27853 \\
\text { e ATCC } 49247\end{array}$ & $\begin{array}{c}0.064-0.5 \\
0.5-2 \\
0.125-1\end{array}$ \\
\hline $\begin{array}{c}\text { ceftriaxone } \\
0.002-32 \text { or } \\
0.016-256\end{array}$ & $\mathrm{TX}$ & 8 & $16-32$ & 64 & E.coli & ATCC25922 & $0.032-0.125$ \\
\hline $\begin{array}{l}\text { gentamicin } \\
0.016-256\end{array}$ & GM & 4 & 8 & 16 & E.coli & ATCC25922 & $0.25-1$ \\
\hline $\begin{array}{c}\text { meropenem } \\
0.002-32\end{array}$ & MP & 4 & 8 & 16 & E.coli & ATCC25922 & $0.008-0.64$ \\
\hline $\begin{array}{c}\text { nitrofurantoin } \\
0.032-512\end{array}$ & NI & 32 & 64 & 128 & E.coli & ATCC25922 & $4-16$ \\
\hline $\begin{array}{l}\text { piperacillin/ } \\
\text { tazobactam } \\
0.016-256\end{array}$ & PTC & 16 & $32-16$ & 128 & E.coli & ATCC25922 & $1-4$ \\
\hline $\begin{array}{c}\text { tetracycline } \\
0.016-256\end{array}$ & $\mathrm{TC}$ & 2 & 4 & 8 & E.coli & ATCC25922 & $0.5-2$ \\
\hline $\begin{array}{c}\text { ticarcillin/ } \\
\text { clavulanic acid } \\
0.016-256\end{array}$ & TLC & 16 & $32-16$ & 128 & E.coli & ATCC25922 & $2-8$ \\
\hline $\begin{array}{c}\text { tobramycin } \\
0.016- \\
\text { 256or0.064-1024 }\end{array}$ & TM & 4 & 8 & 16 & E.coli & ATCC25922 & $0.125-1$ \\
\hline $\begin{array}{c}\text { trimethoprim } \\
0.002-32 \\
\end{array}$ & $\mathrm{TS}$ & 2 & - & 4 & E.coli & ATCC25922 & $0.064-0.25$ \\
\hline
\end{tabular}


Table 2. MIC results for E.coli strains by E-test $(\mu \mathrm{g} / \mathrm{ml})$.

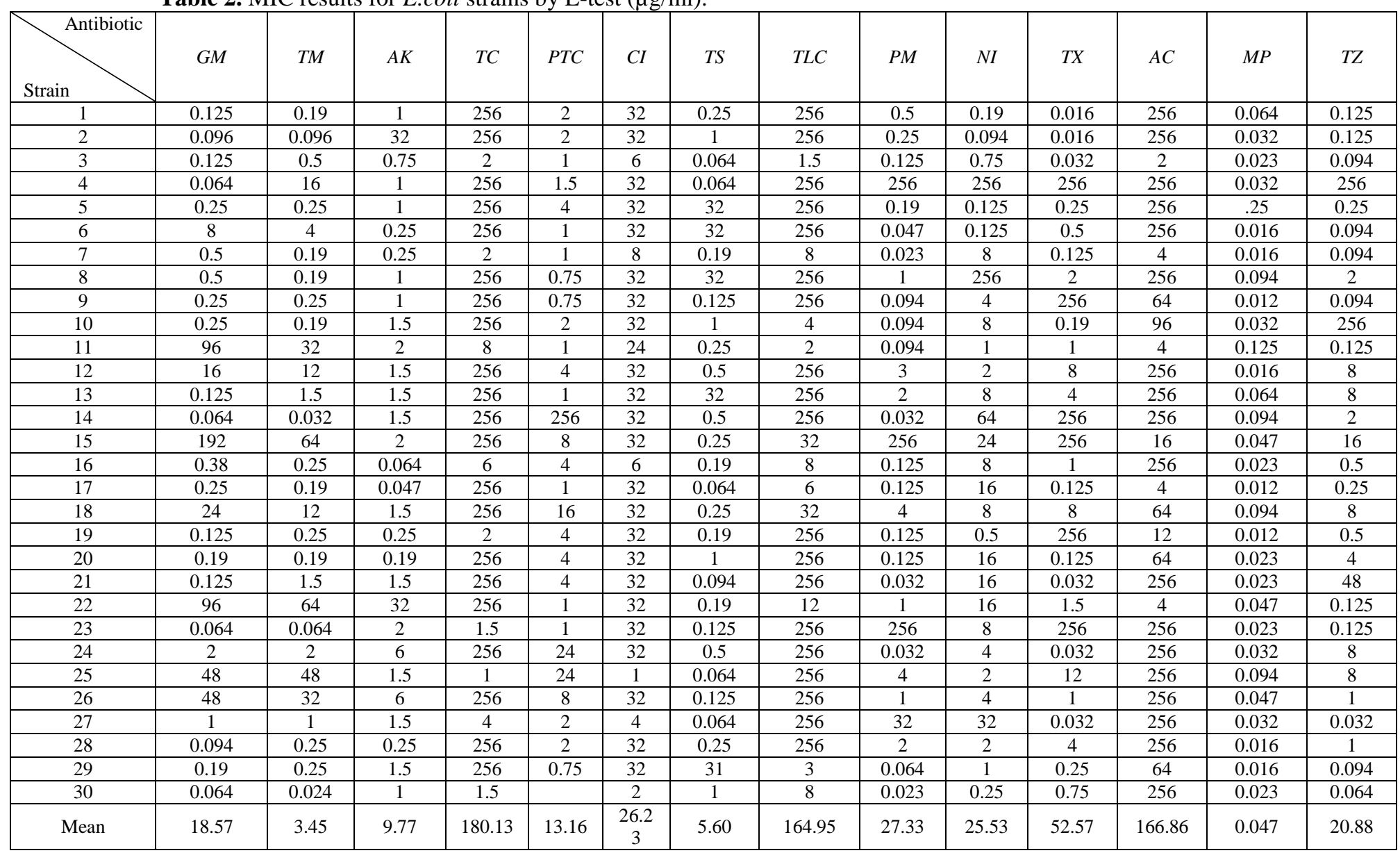

AK; amikacin, AM; amoxicillin, PM; cefepime, TZ; ceftazidime, TX; ceftriaxone, GM; gentamicin, MP: meropenem ,NI; nitrofurantoin, PCT; piperacillin/tazobactam,TC; tetracycline, TLC; ticarcillin/clavulanic acid, TM; tobramycin, SXT; sulfamethaxazoletrimethoprim, CI; ciprofloxacin, AC; ampcillin/cloxacillin.

Table 3. Antibiogram result of E.coli strains.

\begin{tabular}{lccc}
\hline Antibiotic & $\mathrm{S}$ & $\mathrm{I}$ & $\mathrm{R}$ \\
\hline Ceftriaxone & 70.2 & - & 19.8 \\
Tobramycin & 72.6 & - & 26.4 \\
Meropenem & 100 & - & - \\
Ceftazidime & 93.4 & - & 6.6 \\
Gentamicin & 73.3 & 3.3 & 23.3 \\
Ticarcillin/Clavulanic acid & 29.7 & 6.6 & 62.7 \\
Nitrofurantoin & 90.1 & 3.3 & 6.6 \\
Trimethoprim & 83.5 & - & 16.5 \\
Piperacillin/Tazobactam & 90.1 & 6.6 & 3.3 \\
Amikacin & 23.1 & 6.6 & 70.3 \\
Tetracycline & 83.3 & - & 16.6 \\
Ciprofloxacin & 20 & 3.3 & 76.6 \\
Cefepime & 90.1 & - & 9.9 \\
Ampcillin/Cloxacillin & 3.3 & 13.3 & 83.3 \\
\hline
\end{tabular}




\section{Discussion}

Nowadays, around the world there is increasing antibiotic resistance among bacterial infection, especially in hospital wards such as ICU therefore antibiotic resistance pattern determine as main issue is considered to treat infection. In this cross-sectional study, 30 strains of E.coli isolated from Ilam hospitals. Our results indicated E.coli is resistance to Amoxicillin, Tetracycline by $82.5 \%$ and $62.7 \%$ in row. Also, E.coli shown susceptibility to Meropenem, Ceftazidime, Cefepime, Nitrofurantoin, and Piperacillin by $100 \%, 93.4 \%$, and $90.1 \%$, respectively. Most susceptibility was to Meropenem, Ceftazidime, Cefepime, Nitrofurantoin and Piperacillin and lower susceptibility were to Amoxicillin and Tetracycline .

Azar Hadadi and colleague study result confirm our results and shown E.coli susceptibility to Imipenem, Ceftriaxone and Ceftazidime were 91\%, 21\% and $21 \%$ (8).

Zohre Torabi study on isolated E.coli form UTI indicated among 118 E.coli resistance to Ampicillin and Cefexime were $86.2 \%$

\section{References}

1. Lark RL, Saint S, Chenoweth C, Zemencuk JK, Lipsky BA, Plorde JJetal. Four-year prospective evaluation of community-acquired bacteraemia: epidemiology, microbiology and patient outcome. DiagnMicrobiol Infect Dis. $2001 \leqq 15(2): 22-41$.

2. Karlowsky JA, Kelly LJ, Thornsberry C, Jones ME, Sahm DF. Trends in antimicrobial resistance among urinary tract infection isolates of Escherichia coli from female outpatients in the United States. Antimicrob Agents Chemother. 2002;46(8):2540-5 .

3. Foxman B. The epidemiology of urinary tract infection. Nature Rev Urol. 2010;7(12):653-60. and $73.6 \%$ in row. In this study Ciprofloxacin was most effective antibiotic in all wards of hospital to eliminate Urinary Tract Infection. Nitrofurantoin, Ceftriaxone and Amikacin by $51.9 \%, 44.4 \%$ and $8.4 \%$ resistance were in followed row (9).

\section{Conclusion}

Regarding to microbial resistance increasing in hospitals, there is need to collaboration between committee of antibiotic prescribe and infection control committee. To achieve this result, there is need to establish surveillance system in hospital that study microorganism prevalence and their resistance pattern in hospitals.

\section{Acknowledgements}

The authors would like to thank Deputy of Research and Technology of Ilam University of Medical Sciences, Iran, for financial support.

4. Hisanaga $T$, Decorby $M$, Laingk $N$, editors. Antibiotic resistance in outpatient urinary isolates: final results from the North American Urinary Tract Infection Collaborative Alliance (NAUTICA). 41st Annual Meeting of the Infectious Diseases Society of America; 2003;15(3):21-29.

5. Warren JW, Abrutyn E, Hebel JR, Johnson JR, Schaeffer AJ, Stamm WE. Guidelines for antimicrobial treatment of uncomplicated acute bacterial cystitis and acute pyelonephritis in women. Clin Infect Dis. 1999;29(4):745-59.

6. Bradford PA. Extended-spectrum $\beta$ lactamases in the 21st century: characterization, epidemiology, and detection of this important resistance 
threat. Clin Microbiol Rev. 2001;14(4):933-51.

7. Wiener J, Quinn JP, Bradford PA, Goering RV, Nathan C, Bush K, et al. Multiple antibiotic-resistant Klebsiella and Escherichia coli in nursing homes. JAMA. 1999;281(6):517-23.

8. Hadadi A, Rasoulinejad M, Maleki Z, Mojtahedzadeh $\mathrm{M}$, Younesian $\mathrm{M}$, Ahmadi S, et al. [Antimicrobial resistance patterns among Gramnegative bacilli isolated from patients with nosocomial infections: Disk diffusion versus E-test]. Tehran Uni Med J. 2007;65(4):1-10 (Persian).

9. Torabi S, Falak-ul-Aflaki B, Moezzi F. In vitro Antimicrobial Drug-Resistance of Urinary Tract Pathogens in Patients Admitted to Vali-e-Asr Hospital Wards. ZUMS J. 2007;15(61):79-88. 